\title{
Reliability and failure modes of narrow implant systems
}

\author{
Ronaldo Hirata $^{1} \cdot$ Estevam A. Bonfante $^{2}$ Rodolfo B. Anchieta ${ }^{1,3,4}$. \\ Lucas S. Machado ${ }^{1,4}$ - Gileade Freitas ${ }^{1,5}$ • Vinicius P. Fardin ${ }^{2}$ - Nick Tovar ${ }^{1}$. \\ Paulo G. Coelho ${ }^{1,6,7}$
}

Received: 22 April 2015 / Accepted: 23 October 2015 /Published online: 3 November 2015

(C) Springer-Verlag Berlin Heidelberg 2015

\begin{abstract}
Objectives Narrow implants are indicated in areas of limited bone width or when grafting is nonviable. However, the reduction of implant diameter may compromise their performance. This study evaluated the reliability of several narrow implant systems under fatigue, after restored with single-unit crowns.

Materials and methods Narrow implant systems were divided ( $n=18$ each), as follows: Astra (ASC); BioHorizons (BSC); Straumann Roxolid (SNC), Intra-Lock (IMC), and Intra-Lock one-piece abutment (ILO). Maxillary central incisor crowns were cemented and subjected to step-stress accelerated life testing in water. Use level probability Weibull curves and reliability for a mission of 100,000 cycles at $130-$ and $180-\mathrm{N}$
\end{abstract}

Estevam A. Bonfante

estevamab@gmail.com

1 Department of Biomaterials and Biomimetics, New York University College of Dentistry, New York, NY, USA

2 Department of Prosthodontics, Bauru College of Dentistry, University of São Paulo, Alameda Otávio Pinheiro Brisola 9-75, Bauru, SP 17.012-901, Brazil

3 Universidade do Norte Paulista-UNORP, São José do Rio Preto, SP, Brazil

4 Department of Operative Dentistry, São Paulo State University, Araçatuba, SP, Brazil

5 Department of Dental Surgery and Traumatology, Ribeirão Preto School of Dentistry, University of São Paulo, Ribeirão Preto, SP, Brazil

6 Department of Periodontology and Implant Dentistry, New York University College of Dentistry, New York, NY, USA

7 Division of Engineering, New York University Abu Dhabi, Abu Dhabi, United Arab Emirates loads (90\% two-sided confidence intervals) were calculated. Scanning electron microscopy was used for fractography. Results Reliability for 100,000 cycles at $130 \mathrm{~N}$ was $~ 99 \%$ in group ASC, $\sim 99 \%$ in BSC, $\sim 96 \%$ in SNC, $99 \%$ in IMC, and $\sim 100 \%$ in ILO. At $180 \mathrm{~N}$, reliability of $\sim 34 \%$ resulted for the ASC group, $\sim 91 \%$ for BSC, $\sim 53 \%$ for SNC, $\sim 70 \%$ for IMC, and $\sim 99 \%$ for ILO. Abutment screw fracture was the main failure mode for all groups.

Conclusions Reliability was not different between systems for 100,000 cycles at the $130-\mathrm{N}$ load. A significant decrease was observed at the 180-N load for ASC, SNC, and IMC, whereas it was maintained for BSC and ILO.

Clinical relevance The investigated narrow implants presented mechanical performance under fatigue that suggests their safe use as single crowns in the anterior region.

Keywords Dental implants · Biomechanics · Reliability · Weibull · Fatigue

\section{Introduction}

Because osseointegration immediate and long-term success has been extensively reported, the need to expand knowledge on implant-supported prosthodontics success concerning mechanisms involved in the fatigue and failure process has been strongly suggested in a recent systematic review [1]. For single implants, one of the most commonly reported mechanical problems is screw joint instability potentially resulting in loosening and/or fracture of the abutment screw. The second most common failure is loosening or fracture of the abutment with few reports of implant fracture [2]. With variations in implant design and diameter, complication rates should be well understood especially in cases where a narrow implant is under loading, given that stresses will be born and 
distributed to a significantly smaller structure compared to a standard diameter implant (approximately $4 \mathrm{~mm}$ ) [3].

The use of narrow implants, when correctly indicated and placed, has gained significant attention in implant dentistry since it may allow the restoration to be inserted in areas that would require grafting procedures to create enough volume to insert a standard diameter implant. That could increase not only treatment time but also costs and treatment morbidity. Other situations where they may also be indicated are limited prosthetic spaces, as in the maxillary and mandibular lateral incisors [4]. However, little is known about the mechanical performance and expected failure mechanisms of different implant-abutment connection designs of narrow diameter implants subjected to fatigue $[3,5]$. The use of narrow-neck and reduced-diameter implants resulted in an overall increase in stress and strain magnitudes around supporting implants in comparison with support from two standard solid-screw implants [6]. Some manufacturers attempted to decrease the potential failures by increasing the implant diameter and modifying the abutment connection design $[4,5,7]$.

Narrow implants are either presented as one piece, where its coronal portion is prepared to receive the crown, or as two pieces when an abutment is selected to be torqued and to receive the prosthetic crown. Clinical pros and cons aside, the variety of implant-abutment connection designs warrants further investigation so potential differences between systems can be acknowledged. In addition, two-piece implants may present abutments and their screws fabricated as a monolithic piece, which may improve the performance of the system given that spaces for micromotion are eliminated, potentially resulting in increased survival when higher loads operate under function.

Long-term randomized clinical trials are always highly desired to obtain information on the longevity and complication modes of new implant system's design. However, due to high cost and the time consuming nature of this kind of research, laboratory testing involving fatigue is an important step in the hierarchical approach for rapidly understanding material's overall performance before randomized trials can be performed [8]. Fatigue testing is an important tool to understand the probability of survival and failure modes of prosthetic components and implant $[9,10]$. Fatigue testing has demonstrated to be relevant to simulate the mechanical response of prosthesis systems under function $[11,12]$. Fatigue and its related failures are a time-dependent phenomenon with a proportional increase in the incidence of implants and prosthetic component failures observed as time elapses with the system under load [9, 10, 13$]$.

This study sought to evaluate the probability of survival and failure modes of five narrow implant systems, each comprised by a different implant-abutment connection design and restored with maxillary central incisor crowns when subjected to step stress-accelerated life testing (SSALT) in water. The postulated null hypothesis was that two-piece narrow implants from several manufacturers would not present different probability of survival when used for anterior single-unit replacements.

\section{Materials and methods}

\section{Experimental design}

Five different narrow implant systems were selected and divided ( $n=18$ each) as follows: Astra (ASC) OsseoSpeed TX Small implant with $3.5 \mathrm{~mm}$ diameter (Astra Tech, Waltham, MA, USA) with a standard pre-fabricated titanium connection/TiDesign (Astra Tech, Waltham, MA, USA); BioHorizons (BSC) narrow implant of $3.5 \mathrm{~mm}$ diameter (PYR35105, Birmingham, AL, USA) with standard prefabricated titanium connection/PYNEA (BioHorizons, Birmingham, AL, USA); Straumann Roxolid (SNC) narrow neck CrossFit ${ }^{\circledR}$ connection with $3.3 \mathrm{~mm}$ diameter (Straumann, Basel, Switzerland) using a standard pre-fabricated abutment (NC anatomic abutment, Straumann, Basel, Switzerland); Intra-Lock (IMC) narrow implant (3.4 mm diameter) (SQ Connection, Intra-Lock International, Boca Raton, FL, USA) with a standard multilobular connection; and Intra-Lock narrow neck implant (ILO) (3.4 mm diameter) with a one-piece abutment and screw (One Piece Connection, Intra-Lock International, Boca Raton, FL, USA) with a modified square connection (Table 1).

\section{Sample preparation}

Each abutment was connected to the respective implant and vertically embedded in polymethyl-methacrylate resin (Orthodontic Resin, Dentsply Caulk, Philadelphia, PA, USA) leaving $1 \mathrm{~mm}$ of the implant-abutment finishing line exposed above the potting surface. The resin block with the embedded implant-abutment assembly was used as a matrix for fabrication of all samples within the same group.

All groups were restored with standardized central incisor metallic crowns obtained by milling and produced from one single .stl file which fabricated a series of identical samples (Co-Cr alloy, Wirobond 280; Bego, Bremen, Germany). The abutments were tightened with a torque gauge (Tohnichi BTG150CN-S, Tohnichi America, Northbrook IL, USA) according to the manufacturer's instructions, and crowns cemented (Rely X Unicem, 3M ESPE, St. Paul, MN, USA) on the abutments.

\section{Mechanical testing and reliability analysis}

Mechanical testing was conducted with specimens positioned at a $30^{\circ}$ axial inclination, as per ISO 14801:2007, to provide a bending component during fatigue loading which was performed under water at $9 \mathrm{~Hz}$ with a servo-all-electric system 


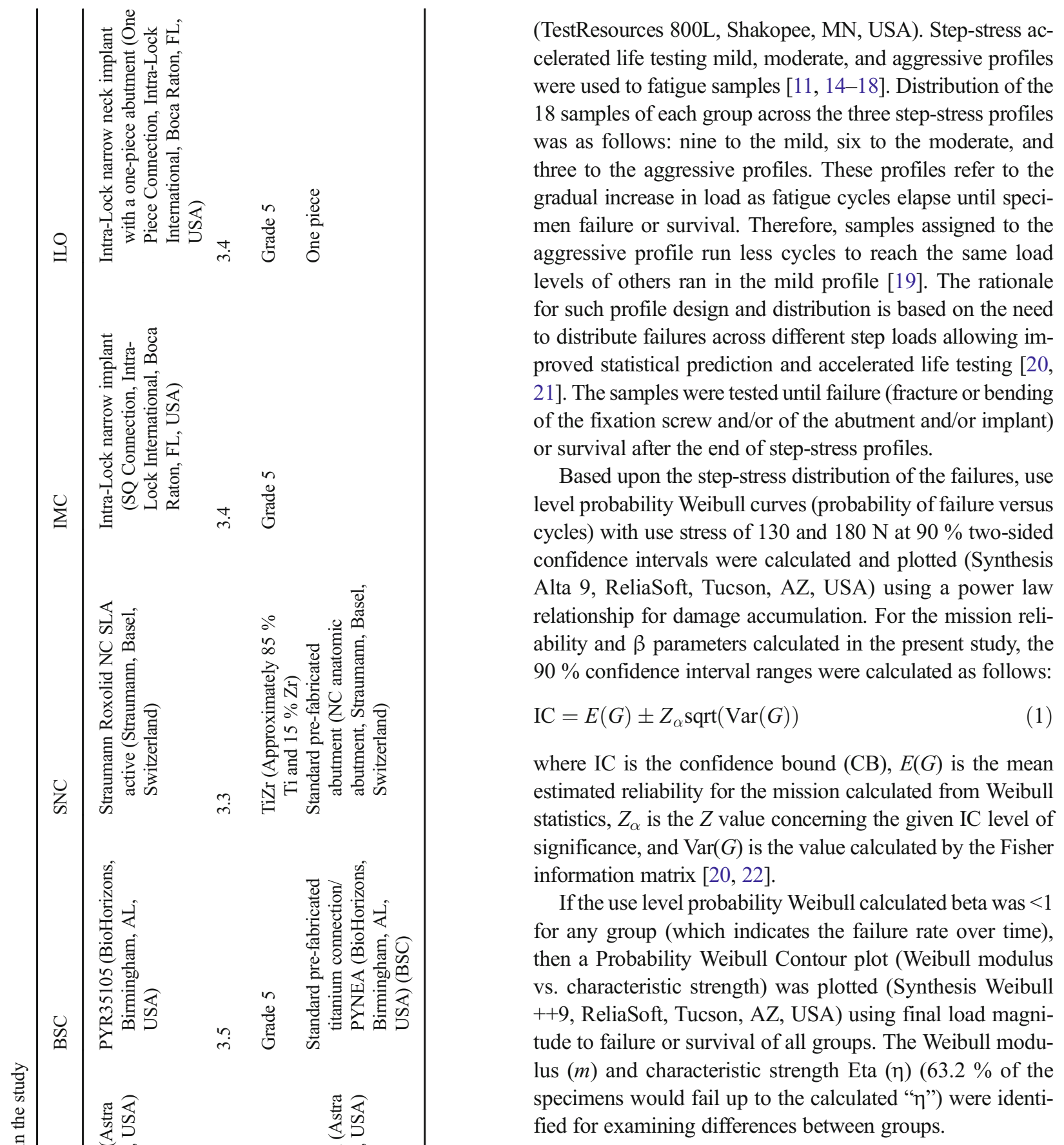

\section{Failure analysis}

The failed samples were inspected in a polarized light stereomicroscope (MZ-APO stereomicroscope, Carl Zeiss MicroIang, Thornwood, NY, USA) and classified according to the failure criteria for comparisons between groups. In order to identify fractographic marks and characterize the failure origin and the direction of crack propagation, the most representative failed samples of each group were inspected under a scanning electron microscope (SEM) (S-3500N; Hitachi, Osaka, Japan) [16, 23]. 
Table 2 Reliability values for a mission of 100,000 cycles show that at $130 \mathrm{~N}$, systems are not different (upper and lower bounds overlap). However, at $180 \mathrm{~N}$, a significant decrease was observed in the reliability of ASC, SNC, and IMC, whereas the reliability of BSC and ILO was maintained. The beta values at the bottom of the table indicate failure rate changes over time.

\begin{tabular}{|c|c|c|c|c|c|c|c|c|c|c|c|}
\hline & & \multicolumn{2}{|l|}{ ASC } & \multicolumn{2}{|l|}{$\mathrm{BSC}$} & \multicolumn{2}{|l|}{$\mathrm{SNC}$} & \multicolumn{2}{|l|}{ IMC } & \multicolumn{2}{|l|}{ ILO } \\
\hline & & $130 \mathrm{~N}$ & $180 \mathrm{~N}$ & $130 \mathrm{~N}$ & $180 \mathrm{~N}$ & $130 \mathrm{~N}$ & $180 \mathrm{~N}$ & $130 \mathrm{~N}$ & $180 \mathrm{~N}$ & $130 \mathrm{~N}$ & $180 \mathrm{~N}$ \\
\hline \multirow[t]{3}{*}{ Reliability $-100,000$ cycles } & Upper & 0.99 & 0.65 & 0.99 & 0.97 & 0.98 & 0.72 & 0.99 & 0.86 & 1.00 & 1.00 \\
\hline & Mean & 0.99 & 0.34 & 0.99 & 0.91 & 0.93 & 0.53 & 0.98 & 0.70 & 1.00 & 0.99 \\
\hline & Lower & 0.94 & 0.07 & 0.97 & 0.77 & 0.81 & 0.30 & 0.92 & 0.43 & 1.00 & 0.99 \\
\hline \multirow[t]{3}{*}{ Beta } & Upper & 3.55 & & 2.37 & & 0.70 & & 3.12 & & 1.81 & \\
\hline & Mean & 2.10 & & 1.34 & & 0.40 & & 2.10 & & 1.05 & \\
\hline & Lower & 1.24 & & 0.75 & & 0.23 & & 1.41 & & 0.61 & \\
\hline
\end{tabular}

Reliability mean values are italicized and refers to the percentage probability of survival of groups at 130 and $180 \mathrm{~N}$

\section{Results}

\section{Mechanical testing}

The mean beta and associated upper and lower bounds $\beta$ value (confidence interval range) derived from use level probability Weibull calculation (probability of failure versus number of cycles) were $2.10(1.24-3.55)$ for ASC, 1.34 (0.752.37) for BSC, $0.40(0.23-0.70)$ for SNC, $3.19(2.22-4.57)$ for IMC, and $1.05(0.61-1.81)$ for ILO (Table 2). The beta value for SNC indicated that strength was the main factor dictating its failure behavior, while failures for the remaining groups were influenced by fatigue and damage accumulation. Note that the beta value (or Weibull shape factor) describes failure rate changes over time where beta $<1$, failure rate is decreasing over time, commonly associated with "early failures" or failures that occur due to egregious flaws; beta $\sim$, failure rate that does not vary over time, associated with failures of a random nature; and beta $>1$, failure rate is increasing over time, associated with failures related to damage accumulation [24].

The calculated Weibull modulus $(m)$ and characteristic strength ( $\eta$, in Newtons) are numerically presented for each group in Table 3 and graphically in the contour plot (Fig. 1). The characteristic strength values for SNC $(220.38 \mathrm{~N})$ and ASC $(237.37 \mathrm{~N})$ were not significantly different from each other, but only the distribution of values of ASC was significantly lower compared to IMC $(270 \mathrm{~N})$ and BSC (286 N) (Fig. 1). The latter two groups (IMC and BSC) were not significantly different between each other, but both presented characteristic strength significantly lower than the ILO $(288 \mathrm{~N})$ which was significantly higher than all others. Differences between groups are depicted in the contour plot (Fig. 1) which represents the values of the combination of both parameters (Weibull modulus and characteristic strength), and differences in specimen population are detected if contour overlap between groups does not exist [25].

The calculated reliability with $90 \%$ confidence intervals for a mission of 100,000 cycles at $130 \mathrm{~N}$ showed that cumulative damage from loads would lead to $~ 93 \%$ implantsupported restoration survival in group ASC, $~ 98 \%$ in BSC, $\sim 85 \%$ in SNC, $\sim 99 \%$ in IMC, and $\sim 100 \%$ in ILO. At $180 \mathrm{~N}$ and same cycle mission, the probability of survival was $<0.1 \%$ ASC, $\sim 77 \%$ for BSC, $\sim 26 \%$ for SNC, $\sim 93 \%$ for IMC and $\sim 100 \%$ for ILO (Table 2 ). Reliability was not significantly different between groups at $130 \mathrm{~N}$. However, at a $180-\mathrm{N}$ load, a significant decrease in reliability was observed for all groups, except for ILO where an overlap was still present between the upper and lower bounds (Table 2). When comparing the reliability between groups at $180 \mathrm{~N}$, only IMC was not significantly different from ILO, whereas the remaining had significantly decreased. Also, the reliability for group BSC was not statistically different from IMC (Table 2).

\section{Failure modes}

All specimens failed after SSALT. When component failures were evaluated together, failures comprised the combination of abutment screw bending or fracture, and abutment fracture

Table 3 Weibull modulus and characteristic strength values for groups

\begin{tabular}{|c|c|c|c|c|c|}
\hline & $\operatorname{ASC}(n=17)$ & $\operatorname{BSC}(n=18)$ & $\mathrm{SNC}(n=18)$ & $\operatorname{IMC}(n=18)$ & $\operatorname{ILO}(n=18)$ \\
\hline Weibull modulus $(m)$ & 11.15 & 9.37 & 12.99 & 7.65 & 17.02 \\
\hline Characteristic strength $(\mathrm{N})$ & $237.37^{\mathrm{b}, \mathrm{c}}$ & $286.54^{\mathrm{b}}$ & $220.38^{\mathrm{b}}$ & $270.15^{\mathrm{b}}$ & $288.09^{\mathrm{a}}$ \\
\hline
\end{tabular}

The same superscript letters indicate statistically homogenous groups 
Fig. 1 a Use level probability Weibull plot shows the probability of failure as a function of elapsed cycles. b Contour plot which is the summary statistics of the failed fatigue samples and their load at fracture during fatigue, or characteristic strength, combined with the information of Weibull modulus. Non-overlap between groups indicates that they are significantly different a
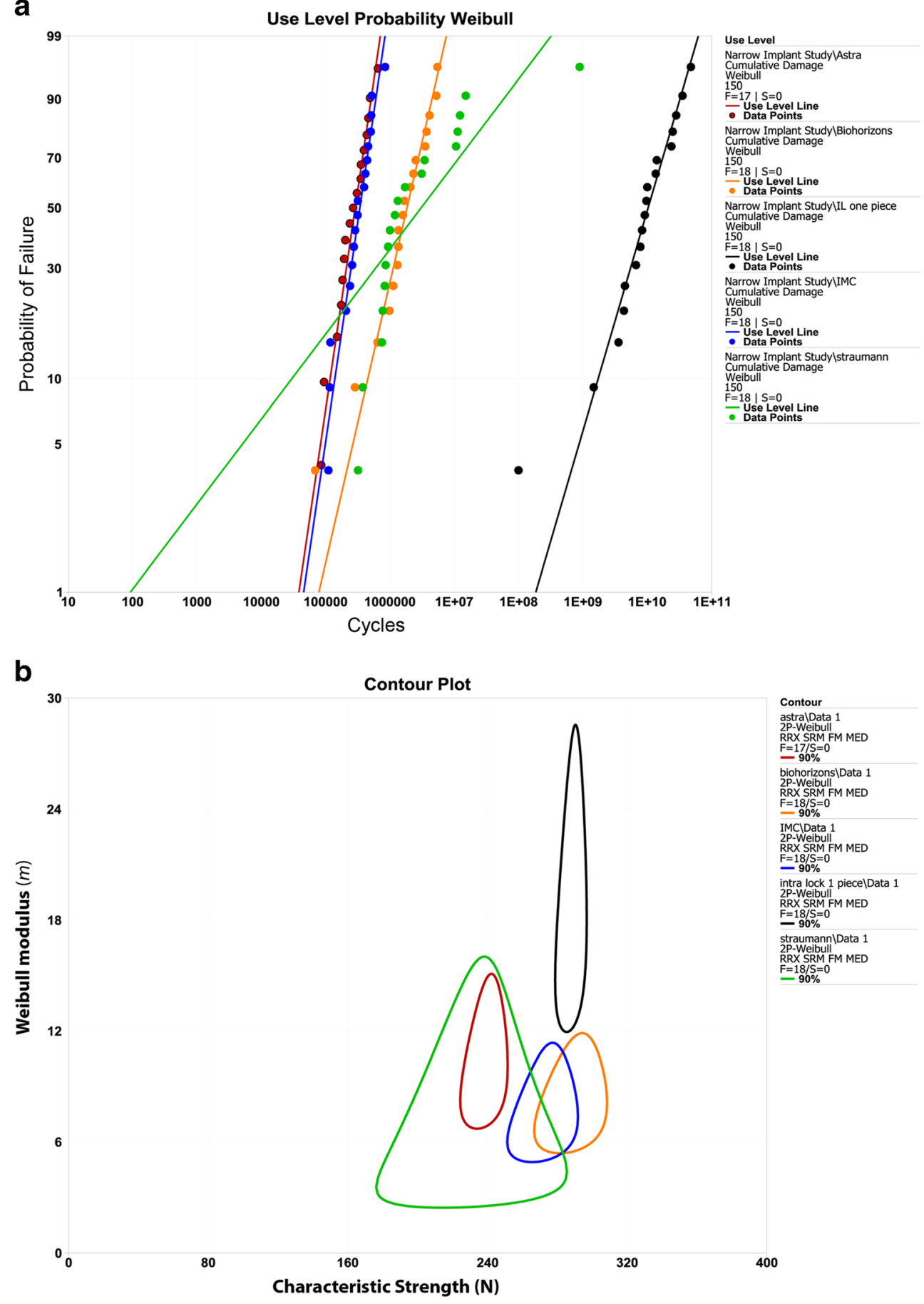

(Fig. 2). Failure modes are described in detail in Table 4. For all groups, failure predominantly involved the abutment screw fracture, and for the ILO group, the abutment fracture. Observation of the polarized light and SEM micrographs of the fractured surface of the abutment screws allowed the identification of fractographic markings, such as compression curl and the identification of the fracture origin at the opposite side along with the direction of crack propagation (Fig. 2).

\section{Discussion}

It is important to acknowledge that no consensus seems to exist in the terminology for narrow or small diameter implants, but as controversies may arise to differentiate them from "mini dental implants" [26] used in orthodontic treatment, it has been suggested that narrow implants have a diameter equal to or greater than $3 \mathrm{~mm}$ [27]. Since narrow 
Fig. 2 SEM micrographs of representative fractures during SSALT showing $(\mathbf{a}, \mathbf{b})$ failure of the one-piece abutment screw system. a A lingual view, where fracture initiated and $\mathbf{b}$ an occlusal view with a compression curl located at the top which indicates that the bottom opposing side is the tensile, where fracture initiated. For the remaining figures, which presented abutments and screws as separate parts $(\mathbf{c}-\mathbf{j})$, a similar failure mode was observed among them with failure confined to the abutment screw and occasionally involving the abutment (as in $\mathbf{i}, \mathbf{j}$ )
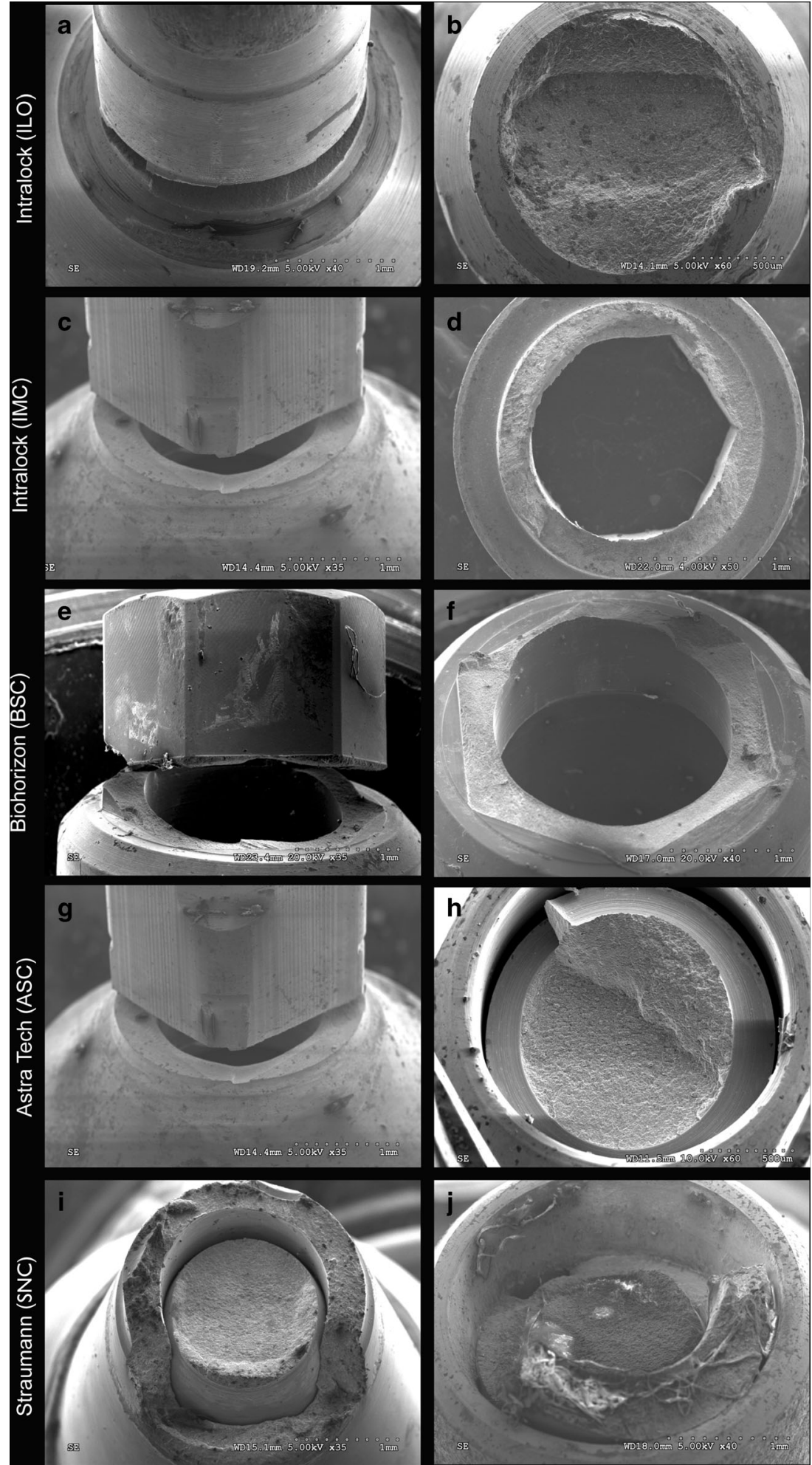

diameter implants have been introduced in attempt to fulfill the challenging clinical situation of thin alveolar crests or limited proximal clearance, the possibility of restoring single-unit prosthesis, as simulated in this study, has raised concerns regarding its mechanical integrity under fatigue loading. As implant diameter decreases, wall thickness at the cervical area will also decrease which seems to be critical in implants with internal connections, as recently shown [13]. Therefore, manufacturers have given substantial attention to more complex engineering designs that would better dissipate stresses 
Table 4 Failure modes after mechanical testing (SSALT) according

\begin{tabular}{llllll}
\hline & ASC $(n=17)$ & BSC $(n=18)$ & SNC $(n=18)$ & IMC $(n=18)$ & ILO $(n=18)$ \\
\hline Implant & $17=$ intact & $18=$ intact & $18=$ intact & $18=$ intact & $18=$ intact \\
Abutment & $3=$ bending & $5=$ bending & $18=$ fracture & $3=$ bending & $18=$ fracture \\
& $14=$ fracture & $13=$ fracture & & $15=$ fracture & \\
Screw & $13=$ fracture & $14=$ fracture & $18=$ fracture & $16=$ fracture & X \\
& $4=$ intact & $4=$ intact & & $2=$ intact & \\
\hline
\end{tabular}

improving the overall mechanical performance of narrow implant systems.

Although the probability of survival for loads averaging $130 \mathrm{~N}$ was high and not different between systems, a slight increase to $180 \mathrm{~N}$ resulted in a substantial decrease for all groups, except for the one-piece abutment/screw system (ILO), and for a very narrow difference in confidence interval also for group BSC. Whereas such result may be expected for the one-piece abutment/screw system, it showed that the presence of an implant-abutment connection and its connecting parts may hamper the performance of most narrow implant systems under more challenging load scenarios. Conversely, the reliability of a system with less connecting parts may be predominantly influenced by the implant and integrated abutment/screw's raw material (i.e., titanium grades or alloys) [28, 29]. The observed differences between the two-piece systems were not expected from an implant diameter perspective alone, given that all four groups were of similar dimensions. Comparing the two-piece implant/abutment groups, only the BSC presented statistically different from the one-piece group at $180 \mathrm{~N}$. Potential reasons for this finding could be attributed to its ability to shield the abutment and its screw preventing them from failing at load levels that lead the remaining groups to failure.

A remarkable aspect observed when comparing the groups for characteristic strength was the non-overlap between the one-piece and all other two-piece systems meaning that the characteristic strength of the former was higher than all others. In addition to this finding, the one-piece system resulted in the highest Weibull modulus, which was expressed in the contour plot by its narrow aspect and indicates that loads required for failure under fatigue occurred under a very defined range for this group. Among the two-piece systems, the only group not intersecting both IMC and BSC, due to its significantly lower characteristic strength, was the ASC system. Considering that implant diameter was identical between BSC and ASC and even lower for IMC, differences in design and fit between connections have likely accounted for the lower characteristic strength observed for the ASC group. The characteristic strength of the IMC was not different from groups BSC and SNC, in spite of its smaller diameter. Possibly its modified connection geometric design (IMC) which presents a four-sided internal configuration provides improved fit, decreasing micromovement between parts [30]. This aspect is of importance as the moment of inertia in bending is proportional to the inverse of the part diameter cube and as such even small decreases or increases in fit will result in exponential variation in the systems' bending resistance. Future studies evaluating the fit of these systems are warranted.

The lack of long-term studies reporting on prosthetic survival rates on narrow implants has recently been pointed out [27], which indicates the need of clinical trials that supports previous in vitro evaluation of their performance considering that an important failure mechanism in metals is fatigue [31]. The step-stress accelerated life testing method utilized in the present study consists in testing the samples at higher stress levels in order to accelerate failures, although every sample is subjected to progressively increasing loads which start at low levels before reaching the above mentioned higher levels [21, 30, 32-35]. These failures are distributed over three different profiles allowing statistical predictions for a given load and cycle mission.

From a fracture evaluation standpoint, abutment screw fracture was the main failure mode for systems other than the monolithic abutment and screw system (ILO). In the latter case, failure was still confined to the abutment/screw system and never involved the implant fractures, which allows subsequent restoration replacement in a clinical scenario. Therefore, regardless of the region where the fracture took place, repair was possible for all groups which is surprising considering that implant wall thickness is engineered to its minimum dimensions.

\section{Conclusion}

The postulated null hypothesis which stated that narrow implant systems varying the connection design within similar diameter would not present different probability of survival when used for anterior single-unit replacements was partially accepted. Although the probability of survival was not significantly different between systems at a 130-N load, an increase in load to $180 \mathrm{~N}$ significantly decreased the probability of survival of all two-piece narrow systems, but the BSC and the one-piece abutment/screw ILO. 


\section{Compliance with ethical standards}

Funding This study was partially supported by Conselho Nacional de Desenvolvimento Científico e Tecnológico (CNPq), grant no. 309475/ 2014-7, by FAPESP nos. 2013/20806-0 and 2014/22859-6, and by Intra-Lock International, Boca Raton, FL, USA.

Conflict of interest The authors declare that they have no competing interests.

Ethical approval This article does not contain any studies with human participants or animals performed by any of the authors.

\section{References}

1. Papaspyridakos P, Chen CJ, Chuang SK, Weber HP, Gallucci GO (2012) A systematic review of biologic and technical complications with fixed implant rehabilitations for edentulous patients. Int J Oral Maxillofac Implants 27:102-110

2. Khraisat A, Stegaroiu R, Nomura S, Miyakawa O (2002) Fatigue resistance of two implant/abutment joint designs. J Prosthet Dent 88:604-610. doi:10.1067/mpr.2002.129384

3. Malo P, Nobre MD (2011) Implants (3.3 mm diameter) for the rehabilitation of edentulous posterior regions: a retrospective clinical study with up to 11 years of follow-up. Clin Implant Dent Relat Res 13:95-103. doi:10.1111/j.1708-8208.2009.00188.x

4. Allum SR, Tomlinson RA, Joshi R (2008) The impact of loads on standard diameter, small diameter and mini implants: a comparative laboratory study. Clin Oral Implants Res 19:553-559. doi:10.1111/ j.1600-0501.2007.01395.x

5. Hirata R, Bonfante EA, Machado LS, Tovar N, Coelho PG (2014) Mechanical evaluation of four narrow-diameter implant systems. Int J Prosthodont 27:359-362

6. Cehreli MC, Akca K (2004) Narrow-diameter implants as terminal support for occlusal three-unit FPDs: a biomechanical analysis. Int J Periodontics Restorative Dent 24:513-519

7. Degidi M, Piattelli A, Carinci F (2008) Clinical outcome of narrow diameter implants: a retrospective study of 510 implants. J Periodontol 79:49-54. doi:10.1902/jop.2008.070248

8. Kitagawa T, Tanimoto Y, Odaki M, Nemoto K, Aida M (2005) Influence of implant/abutment joint designs on abutment screw loosening in a dental implant system. J Biomed Mater Res B Appl Biomater 75:457-463. doi:10.1002/jbm.b.30328

9. Freitas-Junior AC, Rocha EP, Bonfante EA, Almeida EO, Anchieta RB, Martini AP, Assuncao WG, Silva NR, Coelho PG (2012) Biomechanical evaluation of internal and external hexagon platform switched implant-abutment connections: an in vitro laboratory and three-dimensional finite element analysis. Dent Mater 28:e218-e228. doi:10. 1016/j.dental.2012.05.004

10. Parrington R (2002) Fractography of metals and plastics. ASM International

11. Coelho PG, Silva NR, Bonfante EA, Guess PC, Rekow ED, Thompson VP (2009) Fatigue testing of two porcelain-zirconia all-ceramic crown systems. Dent Mater 25:1122-1127. doi:10. 1016/j.dental.2009.03.009

12. Coelho PG, Bonfante EA, Silva NR, Rekow ED, Thompson VP (2009) Laboratory simulation of Y-TZP all-ceramic crown clinical failures. J Dent Res 88:382-386. doi:10. $1177 / 0022034509333968$
13. Bonfante EA, Almeida EO, Lorenzoni FC, Coelho PG (2015) Effects of implant diameter and prosthesis retention system on the reliability of single crowns. Int J Oral Maxillofac Implants 30:95101

14. Martins LM, Bonfante EA, Zavanelli RA, Freitas Jr AC, Silva NR, Marotta L, Coelho PG (2012) Fatigue reliability of 3 single-unit implant-abutment designs. Implant Dent 21:67-71. doi:10.1097/ ID.0b013e31823fcc9f

15. Freitas Jr AC, Bonfante EA, Martins LM, Silva NR, Marotta L, Coelho PG (2011) Reliability and failure modes of anterior single-unit implant-supported restorations. Clin Oral Implants Res 23:1005-1011. doi:10.1111/j.1600-0501.2011.02269.x

16. Almeida EO, Freitas Junior AC, Bonfante EA, Rocha EP, Silva NR, Coelho PG (2012) Effect of microthread presence and restoration design (screw versus cemented) in dental implant reliability and failure modes. Clin Oral Implants Res 24:191-196. doi:10.1111/j. 1600-0501.2012.02437.x

17. Almeida EO, Freitas Jr AC, Bonfante EA, Marotta L, Silva NR, Coelho PG (2013) Mechanical testing of implant-supported anterior crowns with different implant/abutment connections. Int J Oral Maxillofac Implant 28:103-108

18. Freitas AC, Jr., Bonfante EA, Rocha EP, Silva NR, Marotta L, Coelho PG (2011) Effect of implant connection and restoration design (screwed vs. cemented) in reliability and failure modes of anterior crowns. Eur J Oral Sci 119:323-330. doi:10.1111/j.16000722.2011.00837.x

19. Bonfante EA, Coelho PG, Navarro Jr JM, Pegoraro LF, Bonfante G, Thompson VP, Silva NR (2010) Reliability and failure modes of implant-supported Y-TZP and MCR three-unit bridges. Clin Implant Dent Relat Res 12:235-243. doi:10.1111/j.1708-8208. 2009.00156.x

20. Abernethy R (2006) The new Weibull handbook. Dr. Robert B, Abernethy, North Palm Beach, Florida

21. Silva NR, Coelho PG, Fernandes CA, Navarro JM, Dias RA, Thompson VP (2009) Reliability of one-piece ceramic implant. J Biomed Mater Res B Appl Biomater 88:419-426. doi:10.1002/ jbm.b.31113

22. Nelson W (2004) Accelerated testing: statistical models, test plans and data analysis. John Wiley \& Sons, New York, NY

23. Manda MG, Psyllaki PP, Tsipas DN, Koidis PT (2009) Observations on an in-vivo failure of a titanium dental implant/ abutment screw system: a case report. J Biomed Mater Res B Appl Biomater 89:264-273. doi:10.1002/jbm.b.31211

24. Reliasoft (2010) The Weibull distribution and beta. http://www. reliasoft.com/newsletter/1q2001/beta.htm. Accessed Acces Date

25. Nelson W (1990) Book title. John Wiley \& Sons, New York

26. Barber HD, Seckinger RJ (1994) The role of the small-diameter dental implant: a preliminary report on the miniplant system. Compendium 15(1390): 1392

27. Bidra AS, Almas K (2013) Mini implants for definitive prosthodontic treatment: a systematic review. J Prosthet Dent 109:156-164. doi:10.1016/S0022-3913(13)60035-9

28. McCracken M (1999) Dental implant materials: commercially pure titanium and titanium alloys. J Prosthodont 8:40-43

29. Hirata R, Bonfante EA, Machado LS, Tovar N, Coelho PG (in press 2015) Mechanical evaluation of two titanium alloy grades used in implant dentistry. Int J Oral Maxillofac Implant.

30. Freitas Junior AC, Bonfante EA, Silva NR, Marotta L, Coelho PG (2011) Effect of implant-abutment connection design on reliability of crowns: regular vs. horizontal mismatched platform. Clin Oral Implants Res 23:1123-1126. doi:10.1111/j.1600-0501.2011.02257. $\mathrm{x}$

31. Roach M, Williamson RS, Zardiackas L (2005) Comparison of the corrosion fatigue characteristics of CP Ti grade 4, Ti-6Al-4V ELI, Ti-6Al-7Nb, and Ti-15Mo. In: International A (ed) Book title., 
32. Suzuki M, Bonfante E, Silva NRFA, Coelho PG (2011) Reliability testing of indirect composites as single implant restorations. J Prosthodont Implant Esthet Reconst Dent 20:528-534. doi:10. 1111/j.1532-849X.2011.00754.x

33. Almeida EO, Junior AC, Bonfante EA, Silva NR, Coelho PG (2012) Reliability evaluation of alumina-blasted/acid-etched versus laser-sintered dental implants. Lasers Med Sci. doi:10.1007/ s10103-012-1170-8
34. Freitas-Junior AC, Almeida EO, Bonfante EA, Silva NR, Coelho PG (2012) Reliability and failure modes of internal conical dental implant connections. Clin Oral Implants Res 24:197-202. doi:10. 1111/j.1600-0501.2012.02443.x

35. Freitas-Junior AC, Bonfante EA, Martins LM, Silva NR, Marotta L, Coelho PG (2011) Effect of implant diameter on reliability and failure modes of molar crowns. Int J Prosthodont 24:557-561 